\title{
Por uma educação científica que problematize a mídia
}

DOI 10.26512/Ic.v24i0.19850

\author{
Danilo Cardoso \\ Programa de Pós-Graduação Interunidades em Ensino de Ciências \\ Universidade de São Paulo \\ danilo.cardoso.fis@gmail.com \\ Ivã Gurgel \\ Instituto de Física \\ Universidade de São Paulo \\ gurgel@usp.br
}

\section{Resumo}

O objetivo do trabalho é defender que umas das finalidades mais importantes para o ensino de ciências é a de problematizar a mídia. Para isso, primeiramente é feita uma discussão teórica sobre a epistemologia e a educação freireana. Nela, dá-se destaque ao papel da problematização no processo de conscientização. Em seguida, é realizada uma discussão sobre o papel da mídia na sociedade, ressaltando-se seus usos políticos. A partir desta discussão faz-se uma revisão de artigos sobre Educação e Mídia e Mídias e Ensino de Ciências com o objetivo de destacar as principais potencialidades desta aproximação. Por fim, argumentase que somente uma educação científica que problematize a mídia permite uma formação cidadã e crítica.

Palavras-Chave: Mídia, Paulo Freire, Educação e Ensino de Ciências 


\section{Resumen}

El objetivo del trabajo es defender que una de las finalidades más importantes para la enseñanza de las ciencias es la de problematizar los medios. Para ello, primero se hace una discusión teórica sobre las epistemología y la educación freireanas. En ella, se destaca el papel de la problematización en el proceso de concientización. A continuación, se realiza una discusión sobre el papel de los medios en la sociedad, resaltando sus usos políticos. A partir de esta discusión se hace una revisión de artículos sobre Educación y Medios y Medios y Enseñanza de Ciencias con el objetivo de destacar las principales potencialidades de esta aproximación. Por último, se argumenta que sólo una educación científica que problematiza los medios permite una formación ciudadana y crítica.

Palabras-Clave: Medios, Paulo Freire, Educación y Enseñanza de Ciencias

\section{Abstract}

The purpose of the paper is to defend that one of the most important purposes for teaching science is to problematize the media. For this, first a theoretical discussion about Freirean epistemology and education is made. In it, the role of problematization in the process of raising awareness is highlighted. Then there is a discussion about the role of the media in society, highlighting its political uses. From this discussion a review of articles on Education and Media and Media and Science Teaching is presented with the aim of highlighting the main potentialities of this approach. Finally, it is argued that only a scientific education that problematizes the media allows a critical and citizen formation.

Keywords: Media, Paulo Freire, Education and Science Teaching 


\section{Résumé}

Le but de cet article est de défendre que l'un des objectifs les plus importants de l'enseignement de la science est de problématiser les médias. Pour cela, d'abord une discussion théorique sur l'épistémologie et l'éducation de Freirean est faite. Dans ce document, le rôle de la problématisation dans le processus de sensibilisation est souligné. Ensuite, il y a une discussion sur le rôle des médias dans la société, en soulignant ses utilisations politiques. De cette discussion, une revue d'articles sur l'éducation et les médias et l'enseignement des médias et des sciences est présentée dans le but de mettre en évidence les principales potentialités de cette approche. Enfin, il est avancé que seule une éducation scientifique qui problématise les médias permet une formation critique et citoyenne.

Mots-clés: Médias, Paulo Freire, Enseignement et enseignement des sciences

\section{Introdução}

Considerando o atual contexto, no qual o Ensino Médio é reformulado por meio de uma Medida Provisória e uma nova base curricular é proposta, fica evidenciado que a educação e as discussões curriculares são um palco de disputas políticas e ideológicas. Em meio a essas disputas, no campo mais restrito do ensino de Física, é essencial problematizarmos uma questão recorrente em discussões curriculares: "Por que ensinar Física em nossa atual sociedade?" Esta é uma questão que nos leva, necessariamente, a uma reflexão sobre fundamentos educacionais, norteada por questões como: que tipo de educação pretendemos? quem queremos formar? queremos formar pessoas para que tipo de sociedade? Essas questões implicam na discussão de quais conteúdos são mais fundamentais - se é que estes existem - para o tipo de formação que pretendemos, e quais abordagens poderão ser mais adequadas para as finalidades pretendidas.

Entendemos que há uma necessidade crescente em justificar o papel do conhecimento científico na formação dos indivíduos, em especial aqueles que não seguirão carreiras científicas ou afins. Quando consideramos as leis brasileiras que regulamentam a Educação (Lei n 9.394, de 20 de dezembro de 1996), em particular as diretrizes para o ensino básico, notamos que a educação não deve ser propedêutica. Isto é, o ensino médio deve - ou deveria - ter a identidade de etapa final de uma formação mais ampla de todos os cidadãos e cidadãs. Então, para além da compreensão do mundo natural através de teorías científicas, espera-se que a formação dos alunos seja capaz de promover uma postura crítica e participativa destes em um mundo cada vez mais influenciado pela ciência e tecnologia. 
Contudo, o mundo hoje se diversificou muito, tendo como uma de suas características o dinamismo e rapidez na circulação de informações e de novos conhecimentos. As pessoas têm acesso quase irrestrito às notícias e comentários sobre os mais recentes avanços da ciência e da tecnologia, por meio dos mais variados meios de comunicação, especialmente através da internet. Assim, o ensino de ciências não pode se restringir a uma educação meramente formal, descolada da realidade concreta do mundo em que estão inseridos educadores e educandos. Entendemos ser papel da escola formar os cidadãos e cidadãs para uma leitura crítica do mundo e, particularmente, uma leitura crítica da mídia sobre ciência, que tem sido um dos principais meios pelos quais os sujeitos têm acesso a este conhecimento (Jarman \& McClune, 2007, p. 5). Zimmerman e colaboradores (1999) defendem que "claramente a habilidade de ler e avaliar criticamente a mídia é uma importante habilidade para os cidadãos em uma democracia" (Zimmerman et al., 1999, p.1).

Mariana Pezzo (2016) afirma que embora a escola e os diferentes integrantes da comunidade escolar estejam inseridos em relações cotidianas com a mídia e com tecnologias de informação e comunicação (TICs), ainda não há no Brasil, e em muitos outros países, "estratégias e políticas de abordagem da mídia e de suas tecnologias em suas interfaces com processos de ensino-aprendizagem e o ambiente escolar" (Pezzo, 2016, p. 19). Pezzo (2016) parte da convicção de que a abordagem das interfaces entre a produção midiática e o ensino de ciências é indispensável, especialmente para um ensino comprometido com a problematização das relações entre Ciência, Tecnologia e Sociedade (CTS). A respeito desta interface, Pezzo afirma:

além de potencialmente positiva e, também, inevitável, é indispensável a um ensino das ciências comprometido com a problematização das relações entre Ciência, Tecnologia e Sociedade, com a promoção da cultura científica e com a formação de cidadãos aptos a participarem de processos sociais de debate e tomada de decisão cada vez mais permeados por questões relacionadas ao conhecimento científico e tecnológico (Pezzo, 2016, p.20).

Rafaela Bortolin Pinheiro (2015), ao fazer uma breve análise sobre a história da educação no Brasil, afirma que há um enfoque na leitura do mundo sempre dentro de uma linha de raciocínio formal, sem que haja a busca pelo desenvolvimento da autonomia na leitura deste mundo, a ponto de querer questioná-lo ou mesmo reescrevê-lo (Pinheiro, 2015, p. 25291). Esta autora aponta para a importância do binômio comunicação-diálogo na busca por uma educação libertadora, fundamentada na práxis freireana.

O presente trabalho pretende contribuir para a reflexão sobre a relevância de problematizar a mídia no ensino de ciências. Para isto, apresentaremos alguns fundamentos pedagógicos e epistemológicos de Paulo Freire, convergindo para questões relacionadas à comunicação. Posteriormente, buscaremos algumas relações entre as ideias freireanas e o que tem sido discutido por autoras e autores que 
trabalham com educação para as mídias, buscando destacar debates mais específicos do ensino de ciências.

\section{Educação e epistemologia freireana}

Paulo Freire foi um reconhecido pensador brasileiro, tendo se destacado por sua educação libertadora. A pedagogia freireana é baseada em uma concepção problematizadora da educação, que privilegia, sobretudo, o questionamento da realidade social em busca de uma mudança de consciência política (Delizoicov et al, 2002, p. 170).

O diálogo é fundamental para a educação problematizadora. Para Freire, "não há que considerar perdido o tempo do diálogo que, problematizando, critica e, criticando, insere o homem em sua realidade como verdadeiro sujeito da transformação" (Freire, 2015 , p. 64). A problematização da realidade social não significa que devemos nos restringir ao cotidiano dos alunos, aos problemas mais imediatos. Pelo contrário:

O que importa fundamentalmente à educação, contudo, como uma autêntica situação gnosiológica, é a problematização do mundo do trabalho, das obras, dos produtos, das ideias, das convicções, das aspirações, dos mitos, das artes, da ciência, enfim, o mundo da cultura e da história, que, resultando das relações homem-mundo, condiciona os próprios homens, seus criadores. (Freire, 2015, p. 112).

Considerando o conhecimento científico como algo bem estruturado, como um conhecimento historicamente sistematizado, como podemos entender que seu ensino não possa prescindir do diálogo? Para Freire, não se pretende com o diálogo que o educando reconstitua os passos dados no processo histórico de elaboração do saber científico e técnico. O que se pretende com o diálogo é "a problematização do próprio conhecimento em sua indiscutível relação com a realidade concreta na qual se gera e sobre a qual incide, para melhor compreende-la, explicá-la, transformá-la" (Freire, 2015, p. 65).

Defender uma concepção de educação com base na problematização é acreditar tanto em uma educação para a liberdade quanto considerar a própria característica da constituição do saber. Isto porque nenhum cientista construiu conhecimento sem que tenha sido problematizado, desafiado. Isto não implica que todo o homem e mulher que tenham sido desafiados tenham se tornado cientistas. Significa que o desafio é fundamental à constituição do saber (Freire, 2015, p.68): 
[...] Se o conhecimento científico e a elaboração de um pensamento rigoroso não podem prescindir de sua matriz problematizadora, a apreensão deste conhecimento científico e do rigor deste pensamento filosófico não pode prescindir igualmente da problematização que deve ser feita em torno do próprio saber que o educando deve incorporar. (Freire, 2015, p. 68-69)

Além de uma matriz problematizadora, devemos considerar que a produção do conhecimento científico surge através da interação entre sujeitos. Isto implica, de acordo com a concepção freireana, que não basta um sujeito cognoscente e um objeto cognoscível para a construção do conhecimento. Como a interação é fundamental, temos que considerar uma "tríade" sujeito-objeto-sujeito. Para Freire, "todo ato de pensar exige um sujeito que pensa, um objeto pensado, que mediatiza o primeiro sujeito do segundo, e a comunicação entre ambos, que se dá através de signos linguísticos" (Freire, 2015, p. 84). Isto implica que o diálogo é uma relação epistemológica, uma vez que o objeto a ser conhecido vincula dois sujeitos cognitivos, levando-os a refletirem juntos sobre o objeto (Freire, 2011, p. 170).

Freire defende que o diálogo é fundamental para a construção do conhecimento. Esta visão epistemológica, de certo, tem implicações pedagógicas. Implica que o conhecimento do objeto a ser conhecido não pertence exclusivamente ao professor, uma vez que o objeto a ser conhecido está na mediação de professor e aluno como sujeitos cognoscentes: "o objeto a ser conhecido é colocado na mesa entre os dois sujeitos do conhecimento. Eles se encontram em torno dele e através dele para fazer uma investigação conjunta" (Freire, 2011, p. 169). Para Freire a construção conjunta de conhecimento, entre Professor e alunos, é o aspecto fundamental de uma educação libertadora. Apesar de diferentes, professores e alunos devem ser sujeitos cognitivos.

O primeiro teste de uma educação libertadora, para Freire, é "que tanto os professores como os alunos sejam agentes críticos do ato de conhecer" (Freire, 2011, p. 62). Freire destaca, no entanto, que o professor já teve certa experiência gnosiológica para escolher o objeto de estudo. Isto não significa, de acordo com autor, "que o professor tenha esgotado os esforços e todas as dimensões no conhecimento do objeto" (idem). Assim, como a educação para Freire é esta relação entre sujeitos cognoscentes, mediatizados pelo objeto cognoscível, em que o educador deve reconstruir, permanentemente, seu ato de conhecer, ela é, em consequência, um que fazer problematizador (Freire, 2011, p. 109).

Freire destaca dois momentos do que ele chama de "ciclos do conhecimento": um momento de produção e outro em que o conhecimento produzido é conhecido ou percebido. Ele aponta que geralmente tendemos a dicotomizar esses momentos, isolando um do outro. Como consequência disto, "reduzimos o ato de conhecer a uma mera transferência do conhecimento existente" (Freire, 2011, p.22). Isto implica, de acordo com Freire, na perda de qualidades necessárias e indispensáveis tanto para produzir conhecimento quanto para conhecer o conhecimento, como: "ação, a 
reflexão crítica, a curiosidade, o questionamento exigente, a inquietação, a incerteza" (Freire, 2011, p.23). Para Freire "todas essas virtudes são indispensáveis ao sujeito cognoscente" (idem).

Freire reforça a importância crucial da comunicação no processo educativo afirmando que "não há comunicação sem dialogicidade e a comunicação está no núcleo do fenômeno vital" (Freire apud Pinheiro, 2015, p. 25292). A apresentação do mundo como algo estático e que não pode ser mudado configura-se como uma educação antidialógica e que gera, como aponta Pinheiro (2015), o silenciamento dos sujeitos. A autora aponta que os meios de comunicação têm um papel fundamental na manutenção - ou mudança - desta dinâmica perversa de sileciamento. Pinheiro (2015) destaca a crítica de Freire ao uso da mídia no sentido de difundir apenas a versão única e hegemônica dos fatos, "como se o depósito deste conteúdo alienante nelas [nas massas populares] fosse realmente comunicação" (Freire apud Pinheiro, 2015, p. 25293).

Em concordância com sua visão de alfabetização, Freire entendia que a mídia poderia assumir um papel importante a partir do momento em que os sujeitos fossem estimulados a superar a leitura ingênua de textos, sons e imagens e passassem a fazer uma leitura crítica dos meios de comunicação. Pinheiro (2015) afirma que Freire defendia que:

[...] Em relação à mídia, a Educação precisava se basear no estímulo ao pensar crítico e à curiosidade, oferecendo um espaço de formação crítica para possibilitar que os sujeitos deixassem de lado a compreensão ingênua das mensagens transmitidas pelos meios de comunicação e pudessem exercer, de maneira plena e consciente, sua cidadania. (Pinheiro, 2015, p. 25293)

A leitura crítica da mídia passa por compreender os traços ideológicos que as compõem, compreender seu contexto de produção. Como já salientamos, não há produção neutra possível de acordo com Paulo Freire.

Uma leitura de mundo crítica implica o exercício da curiosidade e o seu desafio para que se saiba defender das armadilhas, por exemplo, que Ihe põem no caminho as ideologias. As ideologias veiculadas de forma sutil pelos instrumentos chamados de comunicação. Minha briga, por isso mesmo, é pelo aumento de criticidade com que nos podemos defender desta força alienante. Esta continua sendo uma tarefa fundamental de prática educativo-democrática" (Freire, 2014, p. 124).

Defendemos que a busca de criticidade com relação à mídia sobre ciência deve se dar em dois enfoques principais:

1. Olhar crítico para a produção da mídia, que engloba questões como o interesse econômico dos grupos detentores dos principais meios de comunicação, os usos da linguagem que se faz ao projetar o público leitor, os recursos metafóricos, simplificações, etc. 
2. Olhar crítico para a ciência veiculada na mídia, isto é, buscar uma leitura que vá além da simples decodificação técnica das palavras ditas/escritas. Tratase, também, de ler o não dito, de ler o subentendido, o que está pressuposto. Esse enfoque, além de buscar uma compreensão crítica dos conceitos e teorias abordadas pela mídia, deve priorizar a compreensão da imagem que se faz sobre o contexto de produção da ciência, sobre suas questões epistemológicas, sobre suas interelações com a tecnologia e a sociedade, com o setor econômico, etc.

Para que esses enfoques sejam levados adiante como um projeto de educação, em particular como um projeto de educação científica, é imprescindível que a educação para e pelas mídias seja desenvolvida a partir de uma visão problematizadora e não bancária. Para isso, como defende Pinheiro (2015), é fundamental

\begin{abstract}
a leitura e a discussão de textos de revistas e jornais. Porém, o trabalho não deveria se iniciar com a exigência de que os educandos leiam todos os textos integralmente, mas com a leitura de trechos dessas publicações, trabalhados de forma intensa e fluente para que educandos e educadores tenham tempo para ler, analisar, compreender, criticar e, se possível, reescrever esses textos [...] Neste ponto, a leitura de textos sobre um mesmo assunto em veículos de comunicação diferentes seria fundamental para compreender as múltiplas possibilidades de visões dos fatos e proporcionar aos educandos a oportunidade de se questionarem os motivos de jornais diversos se manifestarem de forma diferente (ou, em alguns casos, exatamente igual) sobre um acontecimento. (Pinheiro, 2015, p.25294)
\end{abstract}

Destacamos, assim, que na concepção freireana a comunicação é fundamental para a construção e apreensão do conhecimento, e que o desenvolvimento de uma visão crítica sobre a mídia é fundamental em uma educação que se pretenda progressista, particularmente em nossa sociedade atual, em que informação é fartamente acessível. Em seguida apresentaremos algumas das perspectivas relacionadas ao debate sobre educação para as mídias no campo do ensino das ciências da natureza.

\title{
A importância de se problematizar a mídia
}

Considerando os anseios atuais da educação em ciências, podemos notar que os processos educacionais devem estar atrelados à permanente busca por uma formação de estudantes que considere suas capacidades críticas e criativas de lidar com o mundo do qual fazem parte como cidadãos. A educação deve buscar possibilidades concretas para que estes desenvolvam níveis de consciência cada vez maiores acerca do mundo e, assim, almejem mudanças radicais a partir de sua reflexão e prática.

A necessidade de reflexão e ação crítica se fazem necessárias em várias esferas da 
sociedade. O recorte do presente trabalho são as mídias, pois nos parece latente o crescente papel que elas desempenham em nossa sociedade. Considerando que a mídia, de certa maneira, molda a visão de mundo das pessoas e, ao mesmo tempo, são utilizadas como meio de expressão e comunicação entre elas, muitos pesquisadores e educadores têm apontado para a necessidade cada vez mais urgente de uma "educação para a mídia". Douglas Kellner e Jeff Share, importantes referências na área de educação e mídia e filiados aos estudos da teoria crítica, destacam a relevância da educação para a mídia afirmando que

Uma vez que os programas de televisão, os videogames, a música e mesmo os brinquedos se tornaram grandes transmissores da nossa cultura, os contadores e vendedores das histórias do nosso tempo, é agora, mais do que nunca, que as crianças precisam aprender a questionar criticamente as mensagens que as cercam e usar a grande variedade de ferramentas disponíveis para expressar suas ideias e exercer plena participação na sociedade. (Kellner \& Share, 2008, p. 689)

Notamos que a mídia desempenha papel relevante na formação da opinião e na construção de visão de mundo das pessoas. Noam Chomsky (2013), por exemplo, propõe interpretações sobre como a mídia influencia na construção de visão de mundo das pessoas. O linguista e filósofo estadunidense, em seu livro: "Mídia: Propaganda Política e Manipulação", foca particularmente no papel que a mídia ocupa na política. De acordo com o autor, "uma sociedade democrática é aquela em que o povo dispõe de condições de participar de maneira significativa na condução de seus assuntos pessoais e na qual os canais de informação são acessiveis e livres" (idem). Contudo, esta não tem sido uma prática comum em diferentes países.

Chomsky (2013, p. 23) aponta que os cidadãos estão reduzidos a espectadores e, para isso, é necessário que essas pessoas sejam mantidas atomizadas, segregadas e isoladas. Este é um dos motivos pelos quais houve - e ainda parece haver - um ataque dos empresários aos sindicatos de trabalhadores. A tática usada pelos empresários, no entanto, tornou-se sutil: "nada de capangas contratados e violência contra os operários", em vez disso, "recursos mais sutis e eficazes da propaganda" (Chomsky, 2013, p.24-25).

Chomsky (2013) traz reflexões sobre algumas práticas usadas para moldar a opinião da população em vista de um interesse político. Uma delas é usar certas representações como realidade. Para Chomsky, "quando se tem a mídia e o sistema educacional sob controleabsoluto e a universidade assume uma postura conformista, é possível vender essa versão" (Chomsky, 2013, p.37). Chomsky dá destaque ao que ele chamou de "percepção seletiva" comentando sobre o papel decisivo da mídia em "selecionar" o que será dado destaque e que, em consequência, moldará a percepção das pessoas. Usa o caso de Armando Valladares, prisioneiro cubano que denunciou supostas torturas sofridas sob o regime de Fidel Castro. Este caso virou uma sensação na mídia norte americana, mas vídeos e outros documentos sobre ele nunca foram apresentados. 
Esta obra de Chomsky não pode ser considerada, a nosso ver, um aprofundamento teórico sobre a mídia, mas uma "denúncia" do que ele considera, a partir de sua posição política, como sendo um uso político e propagandístico da mídia com intencionalidades de alienação das pessoas. Entendemos que esta obra é, sobretudo, uma atuação militante. Neste sentido, Evélyne Bévort e Maria Luiza Belloni (2009), por exemplo, defendem a tradição de uma mídia-educação como uma atividade militante, pautada no princípio de que "não pode haver cidadania sem apropriação crítica e criativa, por todos os cidadãos, das mídias que o progresso técnico coloca à disposição da sociedade" (Bévort \& Belloni, 2009, p.1082). As autoras consideram, no entanto, que a mídia-educação não pode limitar-se à militância.

Ao analisar as aproximações entre a área da educação e da mídia, mais especificamente a área emergente de mídia-educação, Kellner e Share (2008) identificam quatro tipos de abordagens. São elas:

- Medo da Mídia;

- Educação em arte midiática;

- Movimento de Alfabetização Midiática nos EUA;

- Alfabetização crítica da Mídia;

A abordagem conhecida como "medo da mídia" visa, de acordo com os autores, "a proteger ou inocular as pessoas contra os perigos da manipulação e dependência da mídia" (KELLNER \& SHARE, 2008, p. 698). Essa é uma abordagem protecionista que "pressupõe as audiências da mídia como vítimas passivas" (idem). Nossa leitura dos interessantes e importantes apontamentos de Chomsky (2013) nos levou a entender sua abordagem como se enquadrando nesta perspectiva, em especial por carregar em seu discurso, em nossa opinião, uma defesa "antimídia". Kellner e Share alertam, no entanto, que esta é uma abordagem limitada.

Se, por um lado, reconhecemos que a mídia contribui para a existência de muitos problemas sociais e às vezes até os causam, por outro lado, questionamos uma abordagem protecionista, pela sua tendência antimídia, que é demasiadamente simplista em relação à complexidade de nossas relações com a mídia e não leva em consideração o potencial que a pedagogia crítica e a produção de mídia alternativa oferecem para se dar poder às pessoas. (Kellner \& Share, 2008, p. 699).

A abordagem que os autores chamaram de "educação em arte midiática" valoriza, sobretudo, as qualidades estéticas da mídia e das artes. A principal crítica dos autores a respeito desta abordagem é que ela é pouco problematizadora, isto é, que ela ensina aos alunos "habilidades técnicas para simplesmente reproduzir representações 
hegemônicas, sem provocar qualquer problematização, com pouca consciência de implicações ideológicas ou qualquer tipo de crítica social" (Kellner \& Share, 2008, p. 700).

Com relação ao movimento de Alfabetização midiática, os autores consideram que ela fez alguns avanços importantes. Esta abordagem busca incluir a cultura popular e múltiplas formas de mídia (música, vídeo, internet, anúncios, etc), e, ao mesmo tempo, ainda trabalhar dentro de uma tradição de alfabetização na forma impressa (Kellner \& Share, 2008, p. 701). Os autores entendem, contudo, que esta abordagem não é o suficiente para uma "reconstrução democrática da educação e da sociedade" (idem). Defendem, então, um componente crítico para a alfabetização midiática. Este componente deve "transformar a alfabetização em uma exploração do papel da linguagem e da comunicação para definir relações de poder e dominação". Esta preocupação com as relações de poder e dominação vem de um entendimento de que nos discursos da mídia "vivem noções ideológicas profundamente embutidas, de supremacia branca, patriarcalismo capitalista, classismo, homofobia e outros mitos opressivos" (Kellner \& Share, 2008, p. 701). Esta abordagem, alfabetização crítica da mídia, da qual os autores são partidários, inclui, de acordo com os autores, aspectos das três abordagens anteriores, mas "enfocando a crítica ideológica e analisando a política de representação das dimensões cruciais de gênero, raça, classe e sexualidade na economia política e nas relações sociais das importantes empresas de mídia" (Kellner \& Share, 2008, p.702).

Essa perspectiva vai ao encontro, na nossa leitura, às concepções freireanas apresentadas na seção anterior, de uma pedagogia que se constitui no diálogo e na emanciapação dos sujeitos. Assim, como aponta Pinheiro (2015, p. 25295), "a comunicação - e, em um sentido mais amplo, os meios de comunicação - não é somente um recurso de estímulo à leitura, mas de incentivo ao debate, à escrita, à formação de consciência crítica e à libertação a partir de uma ação transformadora" (Pinheiro, 2015, p. 25295). Diante da importância que a educação para a mídia pode ter em uma educação problematizadora/transformadora, Pinheiro conclui que:

Diante de um histórico de supressão da palavra e do pensamento crítico entre alunos e professores e fortemente baseada em um modelo neoliberal de Educação, a escola no Brasil precisa, mais que nunca, ser um espaço em que alunos e professores desenvolvam um processo de contínuo questionamento, seja do que é publicado pelos meios, como também acerca de suas próprias opiniões e representações sobre o noticiado. Isso de maneira que esses sujeitos se sintam instigados e se reconheçam como cidadãos para participar de maneira ativa na sociedade a partir de sua ação transformadora sobre o mundo. (Pinheiro, 2015, p. 25295)

Assim, não basta alunos e professores terem espaço na escola para ler, falar ou escrever, mas realmente ter voz ativa para se expressar e, a partir das mensagens recebidas, produzir suas próprias mensagens de maneira crítica e consciente em conjunto 
com outros sujeitos igualmente autônomos. De receptores passivos e vulneráveis da informação e dos modelos vigentes, essas pessoas precisam ter condições de se tornarem um público consciente, analítico, ativo, criativo e crítico" (Pinheiro, 2015, p. 25295).

\section{Mídia e educação: intersecções e desdobramentos para o ensino de ciências da natureza}

Mariana Pezzo realizou importantes trabalhos sobre educação para a mídia e o ensino de ciências. Em sua dissertação de mestrado (Pezzo, 2011), analisou como se dão os processos de recontextualização e interpretação entre as reportagens da revista semanal Carta Capital e os textos dela decorrentes publicados em Carta na Escola. A autora buscou identificar nos textos selecionados o potencial de concretização dos princípios e metas colocados pela abordagem CTSA (CiênciaTecnologia-Sociedade-Ambiente). O objetivo de Pezzo não foi o de estabelecer um veredito sobre a qualidade do material analisado, mas a busca por compreensões acerca:

Das relações possíveis e produtivas entre os campos da Comunicação Social e da Educação; dos limites e potencialidades do uso de materiais de divulgação científica no ensino de ciências e, de modo mais abrangente, na formação científica em ambiente formais e não formais de públicos com características diferenciadas; e do papel que o uso de materiais midiáticos voltados à veiculação de informações sobre Ciência e Tecnologia pode exercer na superação de desafios relacionados a abordagens de ensino de ciências pautadas nas inter-relações entre Ciência, Tecnologia, Sociedade e Ambiente. (Pezzo, 2011, p.112)

Em sua tese de doutorado, Pezzo (2016) focou suas discussões na Formação de Professores - ainda tendo o ensino de ciências como referência. A autora buscou compreender como Professores em formação em cursos de Licenciatura em Ciências Biológicas, Física e Química relacionam-se com a mídia e quais são suas expectativas em relação à inserção das produções midiáticas no ambiente escolar. Para isto, fez uma análise detalhada de materiais produzidos pelos próprios licenciandos (sínteses individuais e trabalhos em grupo), no contexto de uma disciplina intitulada: "Estratégias para a utilização de notícias de Ciências e Tecnologia no Ensino de Ciências". Os resultados obtidos por Pezzo indicam aspectos que merecem atenção na estruturação de políticas e programas de educação para as mídias na formação de professores, como a permanência de uma visão de "medo da mídia", isto é, uma formação preocupada com a proteção e não com a preparação para o acesso e uso autônomo, crítico e criativo da mídia. Além disso, permanece, de acordo com a autora, a compreensão da mídia como um processo social desvinculado de outros processos de reprodução e transformação social. 
Entendemos que a mídia está intimamente ligada à nossa organização social contemporânea. Analisando especificamente o papel das notícias, Jarman e McClune afirmam que "uma vez que a notícia é evidente no domínio público, a ciência nas notícias também é de domínio público" (Jarman \& McClune, 2007, p. 14). Assim, defendem que os objetivos da educação científica devem estar relacionados, também, à leitura crítica desses materiais de domínio público. Acreditam que uma maneira de preparar os estudantes para seus futuros é engajando-os e preparando-os para a leitura crítica de notícias relacionadas à ciência enquanto estão na escola, visto que essa fonte (dos noticiários) será o principal meio pelo qual terão contato com os assuntos da ciência e assuntos sociais relacionados à ciência (idem).

Renata Ribeiro e Maria Regina Kawamura (2008) afirmam que a "interpretação de notícias sobre ciência e tecnologia veiculadas pelas diferentes mídias e a compreensão de seus significados e das implicações sociais, políticas e ambientais do desenvolvimento científico e tecnológico constituem algumas competências, apresentadas pelos Parâmetros Curriculares Nacionais para o Ensino Médio - PCNEM, a serem desenvolvidas até o final da escolaridade básica" (Ribeiro \&Kawamura, 2008, p. 2). As autoras destacam a importância dada à busca de prover meios para que os estudantes possam se posicionar criticamente diante do mundo, emitindo juízos sobre as informações com as quais têm contato e a necessidade de participação ativa na transformação de sua realidade. Analisando os trabalhos de interface entre ensino de física e divulgação científica, as autoras constatam que essas pesquisas concluem (ou objetivam) que os materiais de divulgação científica contribuem para a formação do espírito crítico dos estudantes, para um olhar crítico sobre a realidade (idem). A tese central das autoras é que "esse olhar crítico para a realidade está relacionado tanto ao processo de produção do conhecimento científico e suas aplicações (foco na ciência e tecnologia) quanto ao de produção das próprias informações sobre ciência e tecnologia e sua veiculação pelos diferentes meios de comunicação (foco na mídia impressa)" (ibdem). As autoras defendem que a articulação e problematização desses dois focos são fundamentais para uma reflexão sobre as formas de incorporação dos materiais de divulgação científica em nossas aulas. Elas concluem que o trabalho com textos de divulgação científica em sala de aula, visando a formação do espírito crítico dos alunos, deve

[...] além de possibilitar discussões a respeito das relações entre ciência, tecnologia e sociedade, dos impactos sócio-ambientais decorrentes do desenvolvimento científico e tecnológico, da política científica nacional etc., também precisa proporcionar uma reflexão crítica e analítica sobre os próprios meios de comunicação, o que envolve o desvelamento de ideologias, o reconhecimento dos recursos utilizados para atrair o leitor e suas influências sobre os conteúdos das informações noticiadas, as estratégias de narrativas e linguagem, a estrutura textual e as características dos textos informativos etc. (Ribeiro \& Kawamura, 2008, p. 11) 
Com relação ao primeiro foco, olhar para a ciência na divulgação científica, as autoras ressaltam as pesquisas que criticam as visões limitadas sobre ciência veiculadas nos textos de divulgação, em especial pautados em uma "mitologia dos resultados", isto é, textos que representam o fazer científico apenas por seus produtos, "ignorando os processos (históricos, sociais e culturais) e os procedimentos (metodológicos) inerentes à atividade científica; na compreensão dos resultados das pesquisas como decorrentes de procedimentos cumulativos e finalistas [...]" (Ribeiro \& Kawamura).

Em um trabalho em que usamos alguns instrumentos metodológicos da Análise de Discurso para problematizar as visões relacionados à Natureza da Ciência em textos jornalísticos sobre a "descoberta" do bóson de Higgs, concluímos que havia nos textos analisados uma imagem subentendida de ciência como um desvelar da realidade, como um empreendimento que alcança gradativamente as verdades sobre a Natureza (Cardoso et al., 2015). Outra crítica que Ribeiro e Kawamura identificam na literatura é a contribuição dos materiais de divulgação científica na manutenção do chamado "mito da neutralidade da ciência". As autoras afirmam que, de acordo com os trabalhos presentes na literatura, as questões relacionadas à neutralidade da ciência aparecem principalmente pela "ausência de visões contraditórias em matérias e artigos sobre ciência" (Ribeiro \& Kawamura, 2008, p. 5). Mariana Pezzo, em palestra ${ }^{1}$ proferida no XXII SNEF, ocorrido em Janeiro de 2017, na cidade de São Carlos, também reforça a crítica relacionada à ausência de contraditório, especialmente em matérias jornalísticas sobre ciência e tecnologia. A jornalista Mônica Teixeira entende que há uma crença de que a verdade da ciência não comporta versões e, assim, o jornalismo científico é isentado de cumprir o "mandamento que interdita a matéria feita a partir de uma única fonte [...]" (Teixeira, 2002, p. 134). Jarman e McClune ponderam, no entanto, ao afirmarem que algumas das fontes usadas pelos jornalistas, em especial quando se trata de revistas especializadas, são revisadas por pares: "[o] fato de a pesquisa ser revisada por pares oferece aos meios de comunicação uma garantia de confiabilidade" (Jarman \& McClune, 2007, p. 45, tradução nossa).

Ribeiro e Kawamura, ao olharem para o segundo foco que propuseram, isto é, para as particularidades dos próprios meios de comunicação e de sua linguagem, focam em três características que são alvo de críticas de jornalistas, cientistas e pesquisadores da área de ensino: Sensacionalismo; Fragmentação; Simplificação. De acordo com as autoras, o sensacionalismo é um conceito polêmico que "apresenta graduações e facetas. Pode englobar desde a utilização de recursos, como suspense e adjetivação, em manchetes ou chamadas, por exemplo, até a extrapolação do real e espetacularização dos fatos" (Ribeiro \& Kawamura, 2008, p. 7). As autoras defendem o valor pedagógico que reportagens sensacionalistas podem ter.

1 É possível assistir à palestra usando a plataforma YouTube, através do link: https://www.youtube.com/ watch?v=VcIT_2WYEeE. Último acesso em 09/07/2018 às $16 \mathrm{h06.}$ 
Talvez uma reportagem sensacionalista possa ser um agente que proporcione a problematização de um dado tema científico em ambiente de sala de aula, por exemplo. Ou possa fomentar discussões a respeito dos processos de produção dos noticiários sobre ciência. Ou, ainda, possibilite, em conjunto com outros tipos de materiais, a construção de um olhar mais crítico sobre os resultados e os processos da ciência e também sobre a mídia. (Ribeiro \& Kawamura, 2008, p. 7)

Teixeira (2002) afirma de maneira taxativa que o jornalismo científico é sensacionalista. Afirma que "é difícil para qualquer jornalista não praticar o sensacionalismo: o acontecimento que não causa espanto, uma sensação, não preenche os requisitos da notícia" (Teixeira, 2002, p. 140). A jornalista destaca que alguns de seus colegas, aderindo à palavra do cientista sem questioná-la, relatam o que vale em condições especiais de um experimento, por exemplo, sem dizer nada sobre essas delimitações de estudo do problema, isto é, tomam a parte como um todo: "afirmar a parte pelo todo, sem mencionar que a parte não é o todo: eis a maneira pela qual a ciência 'traduzida' pelos jornalistas faz-se sensacionalista" (idem).

Com relação à simplificação, Ribeiro e Kawamura afirmam que este processo está relacionado à tentativa de passar de uma linguagem complexa, como a da ciência, para um texto ou discurso acessível ao público de não especialistas. O problema central da simplificação, de acordo com as autoras, "é o comprometimento da precisão dos conceitos e da linguagem científica". Embora não aprofundem nesta temática, as autoras indicam que há correntes que entendem a atividade da divulgação da ciência não como uma tradução de uma linguagem complexa para uma linguagem acessível ao público geral, mas como sendo um processo de construção de um novo saber.

A transformação do conhecimento científico com fins de ensino e divulgação não constitui simples "adaptação" ou mera "simplificação" de conhecimento, podendo ser então analisada na perspectiva de compreender a produção de novos saberes nesses processos. (Marandino, 2004 apud Ribeiro \& Kawamura, 2008, p. 8, grifo das autoras).

Com relação à fragmentação, Ribeiro e Kawamura $(2008$, p. 8) destacam que as informações sobre ciência e tecnologia que recaem nesta categoria são dispersas, descontextualizadas, consolidam uma visão única, e reproduzem os acontecimentos de maneira superficial.

A fragmentação é uma característica marcante das informações. O poder de reprodução dos fatos pela mídia, a agilidade com que os acontecimentos são relatados e a velocidade de circulação das informações são fatores que contribuem para a chamada fragmentação da realidade. Ao leitor cabe selecionar e escolher entre as informações disponíveis aquelas que forem de seu interesse. Cabe também ao leitor articular as peças dessa realidade relatada de maneira fragmentada. (Ribeiro \& Kawamura, 2008, p. 9) 
Além dessas características discutidas acima, poderíamos nos perguntar sobre a parcialidade das notícias, como aquelas destacadas por Chomsky (2013). Jarman e McClune (2007) afirmam que "a objetividade é uma expressão que é ao mesmo tempo um ideal e método jornalístico" (Jarman \& McClune, 2007, p. 48, tradução nossa). Embora apontem que a objetividade seja um ideal jornalístico, os autores reforçam que toda mensagem midiática está embebida de valores e pontos de vista. Entender a construção de notícias é, de acordo com os autores, um objetivo/ princípio (tenet) da alfabetização para a mídia (idem). Concordando que não há objetividade nem neutralidade na construção de um texto, os autores consideram problemática a afirmação de que uma reportagem seja tendenciosa, uma vez que isso implicaria que de alguma forma poderíamos ter construções imparciais (que não fossem tendenciosas), o que para eles "é simplesmente impossível" (ibdem).

Parece-nos razoável considerar que o jornalista envolvido na construção de manchetes sobre ciência tenha alguma proximidade com o conhecimento científico. Não sabemos dimensionar, no entanto, o quanto esse profissional deveria investir em sua formação em ciências. Mesmo considerando a vaguidão desta nossa afirmação, ela nos serve para levantar a seguinte questão: Será que a solução de muitos dos problemas encontrados na divulgação científica, e no jornalismo sobre ciências mais especificamente, seria a formação científica dos profissionais que trabalham nesta área? No limite, se os próprios cientistas tomassem para eles a responsabilidade de falar para o grande público esses problemas seriam amortizados? Não acreditamos que este caminho teria êxito. Como afirma Teixeira (2002, p.141), "o jornalista não precisa conhecer todos os assuntos para poder perguntar sobre eles". A autora defende que o imprescindível no jornalismo é "seus profissionais conhecerem como se usa o contraditório para construir versões mais precisas, em que mais vozes encontram expressão" (idem). Conclui dizendo que "se o jornalista que cobre ciência é um bom jornalista, não se preocupem: a qualidade da divulgação científica virá por si" (ibdem). Neste sentido, notamos a importância de olhar não apenas para o conhecimento da ciência, mas para as condições de produção das notícias sobre a ciência, como apontaram Ribeiro e Kawamura (2008).

Outro problema encontrado na literatura é a complexidade envolvida nos estudos que buscam identificar de quais maneiras as notícias sobre ciências são recepcionadas pelas variadas audiências a que são dirigidas. Jarman e McClune (2007, p. 54) afirmam, de acordo com teorias correntes, que o espectador, ouvinte, leitor ou internauta, longe de ser um receptor passivo de texto de notícias, deve ser reconhecido como um ser ativo no processo de construção de significado. Ou seja, eles defendem que o significado é criativamente construído na interação entre o indivíduo e o texto. Assim, não só a produção de notícias é um processo de construção, mas a recepção de notícias também é um processo de construção. Acreditamos que estas considerações reforçam ainda mais a importância de criamos possibilidades concretas para as pessoas envolvidas no processo de educação para a mídia possam desenvolver não só capacidade crítica 
de leitura de materiais midiáticos, mas também que desenvolvam aspectos criativos de interação com esses meios como forma de ler e se relacionar com o mundo do qual participam. Neste sentido, concluĺmos esta seção com a afirmação de Graça Caldas (2006):

Utilizar a mídia na escola é o primeiro passo para a leitura do mundo. Em contrapartida, é essencial que o exercício cotidiano no uso da mídia na sala de aula não se limite à leitura de jornais, revistas ou dos veículos eletrônicos. Para se ler o mundo a partir dos olhares dos outros,é fundamental que seus leitores aprendam antes a ler o mundo em que vivem, por meio da construção de suas próprias narrativas. Só assim será possível a construção do conhecimento, a transformação do educando em sujeito de sua própria história. A aquisição do pensamento crítico é resultado da inserção e percepção direta do aluno como agente mobilizador na sua realidade.(Caldas, 2006, p. 129)

\section{Considerações Finais}

$\mathrm{Na}$ introdução do trabalho buscamos destacar que vivemos em um momento em que cada vez mais compreensões bem elaboradas sobre porque ensinar ciências se tornaram necessárias. Isto pode ser evidenciado pelo momento político que o Brasil vive, em que mudanças estruturais importantes sobre o ensino médio são aprovadas de modo autoritário, sem que exista na sociedade civil possibilidades consistentes de reação. A apatia política em relação às questões educacionais - mas não somente em relação a elas - vem, entre outras coisas, da falta de esclarecimento sobre questões que envolvem toda a sociedade.

Justificativas que busquem responder a questão anteriormente levantada - por que ensinar ciências? - não podem se limitar, como normalmente é feito, a respostas que se limitem a defender o valor intrínseco de um conhecimento. Respostas consistentes somente podem vir quando esta questão é inserida em um debate mais amplo, que envolve pensar que sociedade queremos construir e qual é o papel de determinados conhecimentos neste projeto.

Para os autores deste trabalho não é possível debater um projeto educacional sem levar em conta que vivemos em uma sociedade dividida em classes, que tem se desenvolvido historicamente aprofundando desigualdades. É preciso considerar que, para que esta realidade se mantenha, é necessário que formas ideológicas se imponham, isto é, a manutenção de uma sociedade desigual somente é possível com a criação de discursos hegemônicos que a justifique. Assim, a defesa de um projeto de sociedade não ocorre apenas nos espaços de decisão, mas também nas disputas simbólicas envolvidas em diferentes interpretações sobre o mundo social.

A formação para a cidadania e uma postura crítica somente se fazem por meio de processos de conscientização sobre como se dão as organizações sociais. 
Uma educação problematizadora, como defendeu Paulo Freire, busca desocultar a realidade mais aparente e colocar em questão as opressões existentes na sociedade. Tradicionalmente, em trabalhos baseados na obra de Freire e que tomam abordagens temáticas como base, a própria realidade vivida pelos estudantes é o elemento principal de problematização. Embora esta prática seja importante e precise ser mantida, cada vez mais ela encontra limites frente a como a sociedade tem se organizado.

A atual sociedade tem aprofundado duas de suas características. A primeira delas consiste em um mundo em que decisões políticas tomadas em diferentes planos se entrecruzam. Dificilmente encontramos problemas "locais", isto é, que não sejam parte de uma rede de problemas sociais mais complexos. A segunda característica que consideramos relevante é a constatação de que vivemos em um mundo em que o real e o virtual não se separam mais, isto é, ambos compõem com o mesmo peso a construção de relações que se reificam.

Há décadas a mídia constrói narrativas para grandes acontecimentos que afetam nossas vidas. Assim, tivemos acesso a, por exemplo, o que aconteceu durante diferentes guerras, produzindo interpretações sobre suas causas e interesses envolvidos. Contudo, hoje a vida cotidiana também está midiatizada. $O$ grande uso de redes sociais faz com que cada vez mais não apenas nosso acesso à informação, mas nossos modos de leitura do mundo sejam midiatizados. Esta sintonia entre formas de percepção do mundo "locais" e "globais" faz com que a realidade mais importante de ser problematizada seja a realidade midiática.

Vivemos a era das Fake News, que influencia as eleições das nações mais importantes - e perigosas - do mundo. A facilidade com que discursos de ódio tem penetrado nas sociedades faz com que "fantasmas" que pareciam superados retornassem. Exemplo disto são os nacionalismos que ganham cada vez mais força na Europa. Grandes grupos de interesse nunca se voltaram tanto ao controle da mídia, consequência direta da chamada "sociedade da informação" (ou desinformação!).

Se estas questões - por sua amplitude e complexidade - parecem distantes dos desafios enfrentados por educadores e educadoras em ciências, esta é somente uma falsa impressão. A mesma sociedade marcada pelas Fake News é a que acompanha movimentos de negação das ciências, como o movimento anti-vacina, os grupos terraplanistas e os que negam o aquecimento global. Se concepções ingênuas de ciências foram até o momento interpretadas como "epistemologias espontâneas" manifestadas por estudantes, agora fica claro que as mesmas são fruto de embates sociais.

Em síntese, a educação atual precisa avançar em projetos humanistas que tenham como base a problematização sobre o que são as ciências. Contudo, esta problematização precisa estar relacionada a um questionamento profundo sobre as mídias e o acesso ao conhecimento. Por fim, consideramos que este processo precisar ser feito com base no diálogo e em ações reflexivas. Um retorno a um cientificismo seria um dos retrocessos mais danosos que poderíamos viver neste momento. 


\section{Referências}

Bévort, E. \& Belloni, M. (2009). Mídia-educação: conceitos, história e perspectivas. Educação \& Sociedade, Campinas, 30, 1081-1102.

Caldas, G. (2006). Mídia, escola e leitura crítica do mundo. Educação e Sociedade, Campinas, 27, 117-130.

Cardoso, D.; Gurgel, I.; Noronha, A. \& Watanabe, G. (2015). Texto Jornalístico sobre Ciência: uma análise do discurso sobre a natureza da ciência. Revista Alexandria, 8(3), 229-251.

Chomsky, N. (2013). Mídia: Propaganda política e manipulação. São Paulo: Martins Fontes.

Delizoicov, D.; Angotti, J. \& Pernambuco, M. (2002) Ensino de Ciências: Fundamentos e Métodos. São Paulo: Editora Cortez.

Freire, P. (2015). Extensão ou Comunicação. São Paulo: Editora Paz e Terra.

Freire, P.(2014) Pedagogia da indignação: cartas pedagógicas e outros escritos. São Paulo: Paz e Terra.

Freire, P. \& Macedo, D. (1990) Alfabetização: leitura do mundo, leitura da palavra. São Paulo: Editora Paz e Terra.

Freire, P. \& Shor, I. (2011). Medo e Ousadia. São Paulo: Editora Paz e Terra.

Jarman, R. McClune, B. (2007) Developing Scientific Literacy:Using News Media in the Classroom. New York: Open University Press.

Kellner, D. \& Share, J. (2008). Educação para a leitura crítica da mídia, democracia radical e a reconstrução da educação. Educação \& Sociedade, Campinas, 29, 687715.

Pezzo, M. (2011). Ensino de Ciências e Divulgação Científica: Análise das Recontextualizações entre as Revistas Carta Capital e Carta na Escola. Dissertação, Centro de Educação e Ciências Humanas da Universidade Federal de São Carlos.

Pezzo, M. (2016). Olhares de Professores de Ciências em Formação sobre as Mídias, sua Inserção no Ensino e a Educação para as Mídias. Tese, Centro de Educação e Ciências Humanas da Universidade Federal de São Carlos.

Pezzo, M. \& Pierson, A. (2013). Especificidades e complementaridade entre Ensino de Ciências e Divulgação Científica: reflexões a partir da análise mensal voltada 
à inserção das "atualidades" no ambiente escolar. IX Congreso Internacional sobre Investigación en Didáctica de las Ciencias, 1, 3093-3097.

Pinheiro, R. (2015). Leitura crítica da mídia à luz de Paulo Freire: Uma reação ao silenciamento de educandos e educadores na História da Educação In: Anais do XII EDUCERE: Formação de professores, complexidade e trabalho docente-. Curitiba: Champagnat, 1, 25281-25297.

Ribeiro, R. A. \& Kawamura, M. R. D. (2008). Ensino de Física e formação do espírito crítico: reflexões sobre o papel da divulgação científica. In: XI Encontro de Pesquisa em Ensino de Física, 1, 1-12.

Teixeira, M. (2002) Pressupostos do jornalismo de ciência no Brasil. In: Massarani, L.; Moreira, I. \& Brito, F. Ciência e Público: caminhos da divulgação científica no Brasil. Rio de Janeiro: Editora UFRJ, 133-142.

Zimmerman, C.; Bisanz, G. L. \& Bisanz, J. (1999) 'Science at the supermarket: What's in print, experts' advice and students' need to know', In: Annual meeting of the National Association for Research in Science Teaching, Boston, MA.

Danilo Cardoso é Mestre em Ciências (Ensino de Física). Doutorando no Programa de Pós-Graduação Interunidades em Ensino de Ciências da USP e professor do Instituto Federal de Educação, Ciência e Tecnologia de São Paulo, campus São Paulo (IFSP$S P O)$. Dedica-se às interfaces entre Divulgação Científica e Ensino de Ciências e entre Epistemologia e História das Ciências e Ensino. É membro do Grupo de Teoria e História dos Conhecimentos ( $\mathrm{TeHCO}$ ).

Ivã Gurgel é Mestre em Ciências (Ensino de Física) e doutor em Educação (Ensino de Ciências), é professor do Instituto de Física da USP. Dedica-se a pesquisas em Epistemologia e História das Ciências, em especial História da Física nos séculos XIX e XX, e Teorias Críticas de Currículo. Coordena o Grupo de Teoria e História dos Conhecimentos (TeHCo). 